\title{
Active tectonics and origin of Tso Morari Lake observed by Remote sensing and GIS techniques
}

\author{
Chandra Shekhar Dubey and Dericks Praise Shukla
}

\author{
University of Delhi, Delhi-1100 07, INDIA
}

Large-scale landscaping processes become strongly influenced by tectonic and geomorphological changes caused to a great degree, by the vertical morphotectonic and climatic zoning which gradually took place on the slopes of the rising mountain ranges. The development of the relief in the northern and central parts of these mountain ranges and near Tso-Morari area the Tibet displays strong exhumation evidences of deep crustal material as well as the features of horizontal movements of the nappe type followed by tectono-geomorphic features of faulting with pronounced differential uplifts on faults, during the Quaternary.

The Tso Morari lake is located between latitude $32^{\circ} 40^{\prime}-33^{\circ}$ $15^{\prime} \mathrm{N}$ and longitude $78^{\circ} 15^{\prime}-78^{\circ} 25^{\prime} \mathrm{E}$, which is about $220 \mathrm{~km}$ southeast of Leh in the northwestern Himalaya at an altitude of $4900 \mathrm{~m}$ and close to the ISZ (Figure 1).

In the present study, we have attempted to identify active faults, tilting of deposits and Neotectonic origin of Tso Morari lake having a dimension of $3 \mathrm{~km} \times 8 \mathrm{~km}$ with the help of Remote sensing and GIS. The study also demonstrates that geomorphological and structural inferences are possible using high resolution TERRA Satellite (ASTER) as well as 30 meter Landsat 7 ETM+ and pseudo Landsat covers of 1990 TM and 2000 ETM data for the arid, often inaccessible and complex terrain of the northwestern Himalaya (Figure 2).

The north-south transect passing near Tso Morari Lake suggest that the SW-directed North Himalayan nappe stack (comprising the Mata, Tetraogal and Tso Morari nappes) was emplaced and metamorphosed by c. 50-45 Ma, and exhumed to moderately shallow depths $(\mathrm{c} .10 \mathrm{~km})$ by c. $45-40 \mathrm{Ma}$. From the mid-Eocene to the present, exhumation continued at a steady and slow rate except for the root zone of the Tso Morari nappe, which cooled faster than the rest of the nappe stack (Schlup et al. 2003).

The Ladakh region of the northwestern Indian Himalaya is rich in quaternary deposits but it has not received much attention. The region was under the influence of tectonic activity and cold climate during the late Quaternary times. Tectonic activity at 50,000 years BP, 35,000 years $\mathrm{BP}$ and 25,000 years BP has been recorded (Phartiyal et al. 2005).

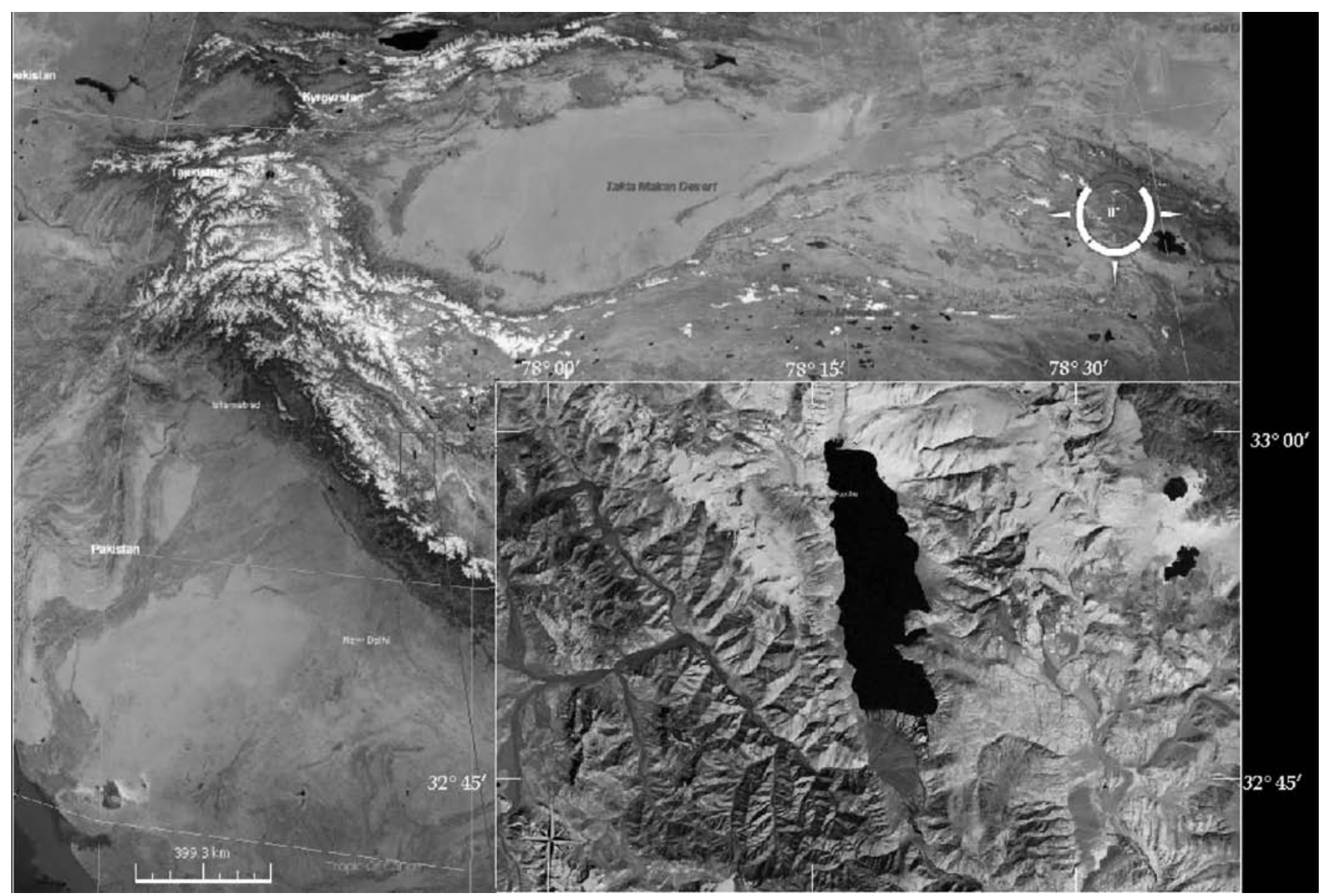

FIGURE 1. Location of the Area 


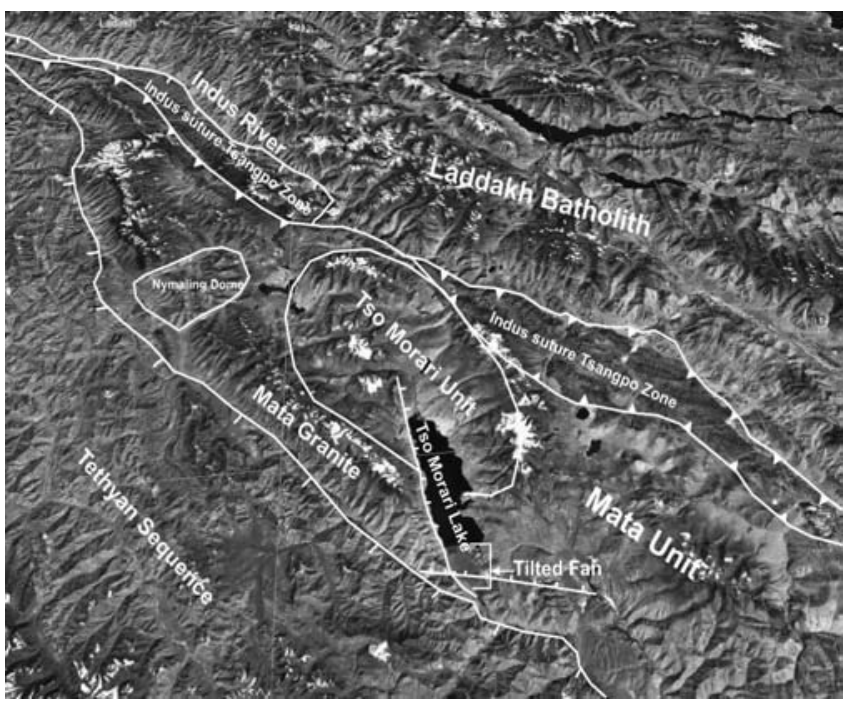

FIGURE 2. Geology and Tectono-Geomorphology of the Area

This fact is corroborated by Aspect at $1^{\circ}$ and Grain classification map derived from SRTM Digital Elevation Model (DEM) using MICRODEM software. Also medium sized recent earthquake activity lie linearly on the fault (source USGS database). It is important to note that most of the recent seismic activity is limited to south of the direction of flow of NW-SE trending river also changed from NNW-SSE to almost NE-SW feeding the Lake. This fault seems to be younger and active and hence has displaced the N-S trending Tso Morari fault (Figure 3).

The LANDSAT ETM 2000 and TM 1990 alongwith the Google earth and NASA world wind pseodo landsat covers depict the damming of the NW-SE trending River on N-S to NNW- SSE trending fault passing upto Kaurik, Leo and Sangla valley (Singh et al. 2007 and this study) and its tributaries by debris avalanches /deposits initiated mainly by tilting of fan due to tectonic

Activity along the WNW-ESE fault lineament. Another prominent feature of this fault is that is cuts the fan at the mouth of Tso Morari lake in such a way that the northern portion takes a concave shape while the southern portion takes a convex shape. The aspect and grain size classification marks the extent of the fault which is well corroborated by the microseismic events draped from google earth over the fault depicting neotectonic activity (Figure 4).

The Tso Morari lake in this region is formed in the late Quaternary due to the damming of the NW-SE trending River and its tributaries by debris avalanches/deposits initiated mainly by tilting of fan due to tectonic activity along the WNW-ESE fault lineament. The seismic activity on this fault is related to neotectonism.

\section{References}

Phartiyal B, A Anupam Sharma, R Upadhyay, Ram-Awatar and AKSinha. 2005 Quaternary geology, tectonics and distribution of palaeo- and present fluvio/glacio lacustrine deposits in Ladakh, NW Indian Himalaya-a study based on field observations. Geomorphology 65 (3-4): 241-256

Schlup M, A Carter, M Cosca and A Steck. 2003. Exhumation history of eastern Ladakh revealed by $40 \mathrm{Ar} / 39 \mathrm{Ar}$ and fission-track ages: the Indus River-Tso Morari transect, NW Himalaya. Journal of the Geological Society of London 160(1): 385-399

Singh S and AK Jain. 2007. Liquefaction and fluidization of lacustrine deposits from Lahaul-Spiti and Ladakh Himalaya: Geological evidences of paleoseismicity along active fault zone Sedimentary Geology 196: 47-57
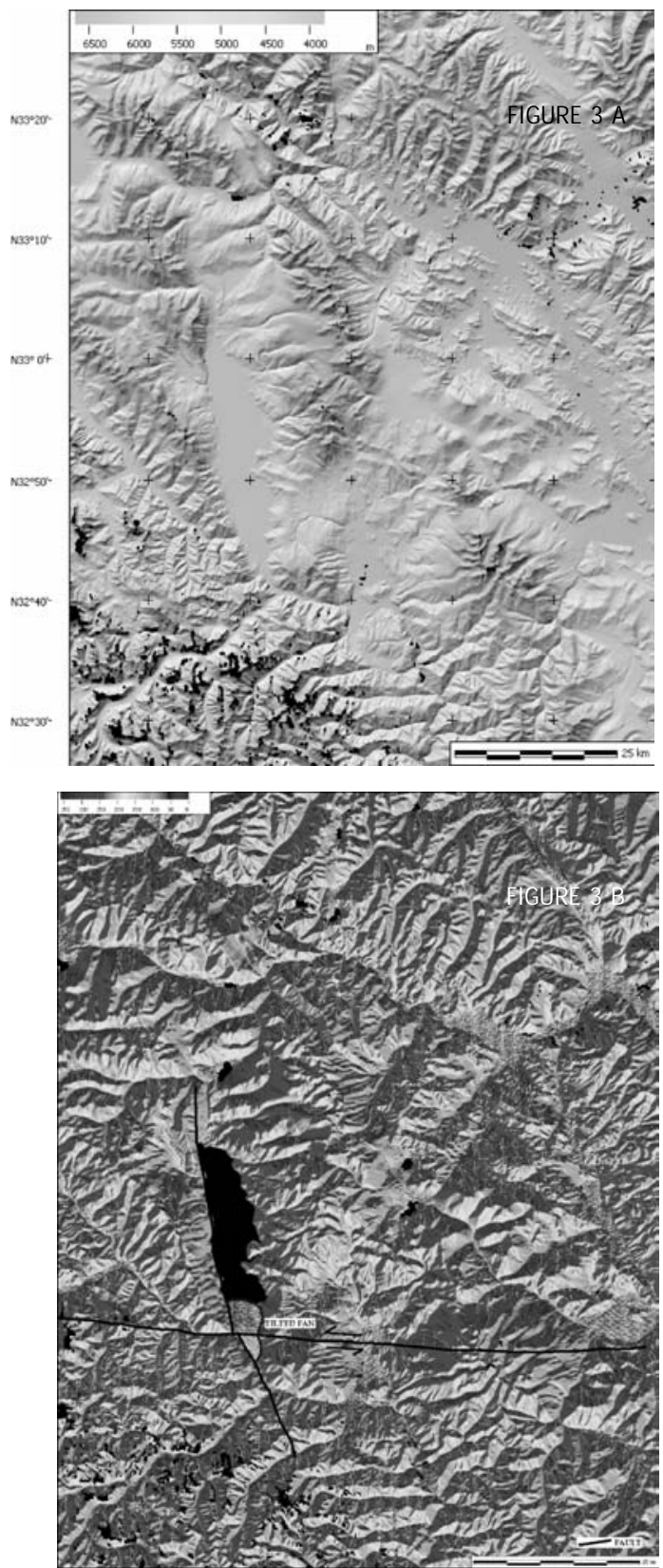

FIGURE 3. A) DEM of the Area B) Aspect at 10 of the area showing tilted Fan

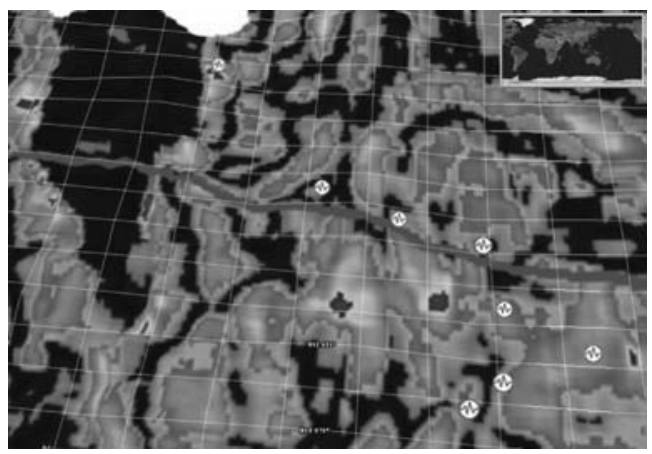

FIGURE 4. Grain size classification map and fault draped on Google showing microseimicity on the identified fault by remote sensed and GIS dataset. 